\title{
10. LEARNING CAREERS OF NON-TRADITIONAL STUDENTS ON EMPLOYABILITY SKILLS
}

\section{INTRODUCTION}

The employability of graduates is a key aim of the Bologna process. Although university graduates are more likely to find a job than non-graduates, the current economic crisis has had an effect on the employability situation of graduates in Spain (Edvardsson et al., 2010; Tholen, 2012). Research indicates that nontraditional students have specific difficulties in achieving a smooth transition into the labour market (Brown \& Hesketh, 2004). University graduates often face a lack of concordance between their university degrees and the demands of the labour market. This problem is exacerbated for non-traditional students who generally need more time than "traditional" students to find highly qualified jobs (Purcell, Wilton, \& Elias, 2007). Furthermore, they are more likely to come across jobs which are below their qualification level and that are, therefore, less interesting and have lower salaries. There is also a mismatch between the graduates' competences and employers' expectations or needs.

This study takes place within the EMPLOY project: a European research project in which six universities are taking part with the aim of improving the employability of non-traditional university students and graduates (youths and adults) in order to foster a smoother transition into the labour market.

Research has, until now, been about the general topics of accessing the job market, and the experiences of non-traditional students who move from university to the labour market have been mostly ignored. This is why it is essential to gather opinions, experiences and perceptions of non-traditional students which take into account their points of view and subjective perspectives. To do so, we present the process and results of a qualitative analysis developed from biographical interviews with non-traditional students. This enables us to acquire new knowledge and perspectives concerning the employability of these students, as well as identifying if higher education institutions are responding to these students needs and endowing them with the competences necessary to carry out a successful transition to a qualified graduate level job. 


\section{NON-TRADITIONAL LEARNERS IN UNIVERSITY AND THEIR EMPLOYABILITY}

The changes in the general state of the economy and the job market are the most significant determinants of work opportunities. A person's employment perspectives are, however, influenced by many factors. This means that not all graduates have similar job opportunities despite having received the same education. These factors include the mode of study (full time or part time), location and mobility, graduates who have previous work experience, as well as their age, gender, race and social class (Harvey, 2001). Regarding the latter series of factors, the discriminatory practices which these graduates could face in the job market are often overlooked in discussions about employability (Morley, 2001).

There are no statistics which shed light on the employability of non-traditional graduate students. All the studies point to the process of integration into the labour market being more satisfactory and successful for university graduates in comparison to the rest of the population. Both, if we speak about work participation and the probability of unemployment, work stability or salary incomes, people with a university degree benefit from better conditions.

However, some of the characteristics linked to non-traditional students (disability, mature age, ethnic origin, low socio-economic capital, etc.) could aggravate the situation of this group with respect to their employability. The level of employability of those with new degrees is going to be determined by various factors related to both the economic situation and some personal and social determining factors. It is therefore necessary to investigate what the starting point is in Spain in terms of the statistics and policies of employability for university graduates and to what extent these statistics and strategic lines consider the differential aspects which characterise the population of non-traditional students and graduates.

The research carried out in Spain by Pastor and Peraita (2014) with data from 2007 to 2013 shows that employment prospects have been destroyed for people at all educational levels (including short university cycles), with the exception of graduates, where there has even been a certain growth. Nonetheless, in the samples of these studies the set of characteristics which can affect the probability of having a job (gender, age, nationality, level of studies, the branch of these studies and even the region of residence) are controlled. This is why we lack information precisely concerning if these work benefits can affect non-traditional graduates to the same extent or not.

Another report about the employability of university graduates in Spain comes from the Ministry of Education, Culture and Sport (2015). It compiles statistics about the work integration of university students based on the rate of registration for Social Security $^{1}$ for the cohort of graduates for the academic year 2009-2010, for which information is facilitated from 2011 (one year after the students finished their studies), 2012, 2013 and 2014. Working on Social Security registration we can obtain certain 
information about the quality of the employment (if it is permanent, temporary, fulltime and in keeping with their educational level) of the university students.

The first data which we have is that employment increases with the passing of time. Of the university graduates of the 2009-2010 course, $43.4 \%$ (42.9\% of the women; $44.3 \%$ of the men) are registered for Social Security one year after finishing their studies, $55.6 \%$ are registered two years after, 58.6\% three years later and $64.4 \%$ four years after (64.1\% of women; $64.9 \%$ of men).

These results vary according to the age section (see Table 1). Those who got their degrees when they were younger (under 30 years old) have registration rates lower in the first year than those who are over 31 . Yet this data could be due to the fact that in the higher age sections it is frequent for students to already be in the job market before finishing their studies. This is why it is necessary to add that as time passes the graduates who finished their studies when they were between 25 and 40 years old are those who attain higher registration rates, while those who finished them when they were over 40 are delayed, their registration rate hardly varying with respect to those who have recently graduated.

Table 1. Social security registration rates in the first and fourth year after graduation according to age group (MECD, 2015)

\begin{tabular}{lcc}
\hline & $\begin{array}{l}2011 \\
\text { (first year after graduation) }\end{array}$ & $\begin{array}{l}2014 \\
\text { (fourth year after graduation) }\end{array}$ \\
\hline Total & $43.4 \%$ & $64.4 \%$ \\
Less than 25 years old & $33.1 \%$ & $63.8 \%$ \\
$25-30$ years old & $48.6 \%$ & $64.9 \%$ \\
$31-40$ years old & $63.1 \%$ & $66.6 \%$ \\
Over 40 years old & $61.4 \%$ & $61.3 \%$ \\
\hline
\end{tabular}

In addition to this, the transition from university to the labour market is an area explored in several Spanish publications. Calvo and Fernández (2013) studied the programmes of "first young employment" and Alonso (2010) focused on different career patterns, creating several typologies about the ways of navigating from higher education to work. Some studies researched on factors that hinder and enhance good working itineraries (ANECA, 2009; Pastor \& Peraita, 2014).

Nevertheless, we lack research which goes thoroughly into the competences of employability and transitions to the job market of non-traditional university graduates. The viewpoint which underlies this absence of a specific focus is that once in higher education there is equality among students, irrespective of their social or family background (Monteagudo \& Ballesteros, 2011). Consequently, we also expect that the university degree will itself eliminate the disadvantageous background which some students have. 
The capacity of universities to provide their students and graduates with employability cannot be precisely evaluated by using uniquely "objective" indicators, such as job and salary perspectives. This data needs to be supplemented by information which sheds light more directly on the graduates' capacities. That is to say, on their competences, paying special attention to non-traditional students.

Our study aims to contribute to improving this situation by increasing the information available concerning the employability of non-traditional students. To do so, we draw on their experiences. These are our research aims:

- To analyse the university education received concerning employability.

- To understand employability from the perspective of non-traditional students.

- To identify the factors which foster or hinder the employability of non-traditional students.

\section{METHOD}

The methodological options emerge from our main aim: to understand the employability of non-traditional students. To do this we have followed a qualitative approach in order to analyse these students' perspective of employability. We identify their relation with university education and the factors which foster or hinder it. We have opted to carry out biographical interviews in which the narrator and researcher have gone deeply into those aspects which are deemed necessary. In this context, the biographical interview is the key axis for the information gathering process.

We have centred on working with a few subjects (seven) whose series of specific characteristics can provide us with a view of the problem which is broad and selected enough. The choosing of the participants was carried out based on a series of criteria which we established as relevant for our study: to be in the last year of the degree course at the University of Seville and to correspond to one or more characteristics of the typical non-traditional profile.

We have managed to represent diverse profiles. We had three women and four men, each from a different knowledge area (Arts and Humanities, Sciences, Health Sciences, Engineering, Architecture, Social Sciences and Law) - except from the latter, as we had an easier access to these students in the other fields. After gathering the data through biographical interviews, we carried out an analysis of their content. During this process we have kept the aims and questions with which we began the research very much in mind. Given the characteristics of the questions, it seemed appropriate to undertake a qualitative analysis of the content of the answers based on the identifying of categories. Hence, after an independent reading of the interviews, the different category sets were extracted. These sets fall into three dimensions: a valuation of the university education, the factors which influence job placement and conceptions of employability. 


\section{RESULTS}

Now we present the results of the analysis carried out about the three previouslyformulated dimensions: a valuation of university education, the factors which influence job placement and conceptions concerning employability.

\section{Valuation of University Education}

First and foremost, the students perceive that the contents of the study plans are not proportionate with the time allocated. Furthermore, they highlight the lack of transversal subjects which deviate from the specific competences of the degree and study in greater depth other generic competences, mainly concerning emotional and social skills.

The competences are in social skills. Because today's world does not require a degree, although it seems to do so, it demands an interest in doing things, in progressing. (Boti)

Well, I think what most needs to be improved in the healthcare degree is the human aspect, humanistic, I don't know what's the exact term (...) I've missed this a lot, them teaching you to empathise and to deal with people and to deal with them well, a bit of psychology or I don't know what it could be, but I miss it. (Botico)

Regarding the subjects, there is an almost unanimous wish to broaden the practical contents and set up a stronger relation with the theoretical contents.

There's too much theory without practice so they don't combine, it's like nothing. (Gracia)

What's bad about the engineering degree is it's all theoretical, you don't do anything practical there, nothing, what you do in practice is to hang out. (...) I think it should be more centred on practice, I think that is important. (José Antonio)

A general approval is given to incorporating internships into the study plans, even for those students who belong to degrees in which this is not obligatory or not included in their study plans.

In the biology degree we don't have internships, I think having them would be positive because it helps you to work in other areas, not only in the university and you get more involved I think. (Bio)

We however find some complaints referring to the mismatch between the tasks carried out in internships and the reality of work, others which describe how those students doing internships are abused by employers and others concerning their time programming and the content of the previous workshops. 
There's an important shortfall in the subject of internships. Firms normally use pedagogues to do other duties which are not really what a pedagogue should do. (...) The faculty's internships ought to be the reality of what you're going to come across after or of what you're supposedly going to come across after and it's not like that. (Boti)

There are some who take advantage of the students, some or most. In the interview they told me: "we're going to train you" (...) and they also said this to some colleagues who they interviewed but it was a sham. (José Antonio)

The students went against their traditional profile of the methodology based on data transmission and theoretical contents. Alternatives are proposed to foster significant learning, such as carrying out debates, presentations, group work and a greater participation in class. Also, to favour the crossover to the job market a greater relation between the university and employers was proposed, including the latter in the classrooms.

Only one teacher took us to a pharmacist, to an inspector of chemists at a national level and another at a regional level, people who had devoted themselves to orthopaedics, people who had set up a herbalist's shop but who had a pharmacist's degree. (Botico)

With the group discussions we rebutted the teacher-student idea a bit, that hierarchy which is at times adverse to education. (Alejandro)

We did few presentations, little group work (...), so I think there should be a lot more for the students to come out of their shells. (Gracia)

It also helps to work in a group because really when you leave here, in the world of work you're going to have to work with all kinds of people, you're going to have to fit in with all kinds of people. (Bio)

\section{Conceptions about Employability}

The conceptions about employability vary among the students belonging to the field of pure sciences and health sciences, and those of social sciences and humanities. The former stress the specific competences which are characteristic of the degree and having skills to profit from, and to produce in the least time possible.

I think you have to have something that is a bit different that the firm needs (...) for example, if you have to model in 3D you need computer programme knowledge like Catia V5. (José Antonio)

A person who develops their mind to do things more easily is sure to suit my firm more than another person (...). If a job can be done in five ways you must know how to develop it in the easiest way. (José Antonio) 
However, the students who belong to the field of social sciences and humanities highlight the generic competences referring to personal attributes. They specify emotional, social and communication skills, having a vocation and proactive attitude, as well as the ability to be self-taught and self-sufficient when acquiring education. Regardless of the degree, they all valued competences in languages and having experiences of mobility.

Languages are obviously essential, whether we like it or not, it's like that and it's going to be like that. If you don't have a second language you're going to be almost illiterate because the world is increasingly more globalised and it's going to be like that (...). For example, of course, experiences of mobility, that is how it has to be. (Boti)

\section{Factors Which Influence Employability}

One of the most influential job-seeking factors is to have work experience. Having it becomes a facilitating factor (an advantage for mature students) and not having it is a hindrance. Also, most of the interviewees coincide in stating that not having contacts which facilitate employability becomes a barrier.

I don't have many contacts, often it's much easier to find a job through a contact with someone who gives you an opportunity. (Alejandro)

Something which makes looking for a job difficult ... perhaps it's not what it's about but pulling strings (...) what I don't understand is there being five candidates and one, who's somebody's niece, well they choose her even though the other four have twenty times more knowledge about the job than her. (José Antonio)

Not having a variety of degrees, knowledge of languages or experience abroad is added to the list of factors which hinder employability. This situation is made worse by not having the economic resources to overcome them. It is specified that the university where you are from can also become a barrier if a comparison is made with students belonging to other, more prestigious universities.

For some of those interviewed, having a "non-traditional" profile is considered to be an additional problem. Examples are immigrants, those who have a low socio-economic level, being a woman and mature students; although the latter do, nevertheless, have the advantage of their greater resources for self-employment.

Because of being an immigrant there will be certain things, certain stereotypes that in some way you go to a firm and they say: "oh, those no", but I think that the work you do speaks for itself. (Gracia)

Sadly the weak point is age. I don't know why, don't ask me why but it's age, I don't understand it. (Boti) 
I know that out there I'm a person who's at risk of exclusion (...) because I'm a woman, I'm over forty-five and I'm middle class, though I'm educated the social class still counts. (Justa)

To overcome the subject of age the easiest thing is to make up your own story. Self-employment because it's easier for me than for youngsters, I've more resources for that, I've more friends, I know more people, and other ways. (Boti)

As external factors, they point out our country's current crisis; not only the economic crisis but also certain policies and few career opportunities, especially in the field of humanities. Work conditions, particularly those with respect to schedules, can become a problem because of having to reconcile them with another job, with education or with the family. Family support is vital when making the move into the labour market.

There are people who don't care about working in the afternoon or in the morning and others who do, but the fact of going one week in the afternoon, one week in the morning of course complicates you being able to enrich yourself or being able to continue developing something else in parallel. (Alejandro)

Yes, I've got a family environment which I'm getting support from (...).I'm here thanks to them, when I've been desperate they've given me encouragement. (Justa)

In Spain for philosophy (...) it seems we only want to fabricate teachers who're going to fabricate future teachers continuing a cycle, I don't know where it's going to end up (...). Nor, for better or for worse, is the panorama very good for these fields in Spain. (Alejandro)

\section{CONCLUSIONS}

Yorke (2006) differentiates two approaches to employability: one centred on employment boosted by those factors which enable people to move into, make progress in or stay in employment; and another whose focus is on competences and skills which higher education students acquire during their studies. To understand employability from the students' perspective, we can conclude that all the students interviewed have a concept of employability based on competences and not on employment.

The competences of employability which the participants highlight vary according to the field of knowledge to which they belong. Some students who are doing a degree in pure science or health sciences underscore specific competences (Teichler, 2011), namely those related with particular professions. However, the students who belong to the field of social sciences and humanities emphasise generic competences (communication, emotional and social skills, teamwork, etc.).

In line with the contributions of Harvey (2001), in our study we have noted factors which influence a person's employability: previous experience (which is an 
advantage to have and a hindrance to not have), his/her age, gender, race and social class. That is to say, the profile of a "non-traditional" student is also considered as a barrier given that, as Purcell, Wilton \& Elias, 2007 pointed out, they need more time to find jobs than "traditional" students. Only the possibility of self-employment is noted as a factor in their favour.

It has also been demonstrated that, as Bermejo (2011) indicated, these kinds of students have trouble combining their studies with work or with other family responsibilities. This is the reason why they come across limitations of availability in their work schedules and conditions. Not having economic resources to broaden their education, gaining in knowledge of languages or having experiences of mobility are added to this list of obstacles, as well as not having the contacts which facilitate the transition into work.

As Monteagudo and Ballesteros (2011) noted, it is sometimes assumed that after having begun higher education there is equality among students, irrespective of their social or family backgrounds. Yet we have found out in this study that there are other factors which are overlooked by higher education policies and institutions.

\section{NOTE}

1 The Social Security registration is measured with a fixed date of March 23rd. of the calendar years following the conclusion of university studies.

\section{REFERENCES}

Agencia Nacional de Evaluación de la Calidad y Acreditación. (2009). Los procesos de inserción laboral de los titulados universitarios en Españ. Factores de facilitación y de obstaculización. Madrid: ANECA.

Alonso, M. A. (2010). Evaluación del potencial de inserción laboral y patrones de carrera. Revista de Educación, 351, 409-434.

Ballesteros, M. A., \& Monteagudo, J. (2011, April). Social and cultural dimensions of higher education as context to understand non-traditional students. Paper presented at RANLHE Conference on Access and Retention: Experiences of non-traditional learners in Higher Education, Seville, Spain. Retrieved from http://www.dsw.edu.pl/fileadmin/www-ranlhe/files/Monteagudo_Ballesteros.pdf

Bermejo, L. (2011). Aprendizaje a lo largo de toda la vida. Madrid: IMSERSO.

Brown, P., \& Hesketh, A. (2004). The mismanagement of talent: Employability and jobs in the knowledge economy. Oxford: Oxford University Press.

Calvo, F. J., \& Fernández, M. F. (2013). El contrato de 'primer empleo joven'. In M. F. Fernández \& F. J. Calvo (Eds.), La estrategia de emprendimiento y empleo joven en la ley 11/2013: desempleo, empleo y ocupación juvenil. Albacete: Editorial Bomarzo.

Edvardsoon, B., Gerbauer, H., \& Bjurko, M. (2010). The impact of service orientation in corporate culture on business performance in manufacturing companies. Journal of Service Management, 21(2), 237-259.

Harvey, L. (2001). Defining and measuring employability. Quality in Higher Education, 7(2), 97-109.

Ministry for Education, Culture and Sport. (2015). Datos y cifras del sistema universitario español. Curso 2014-2015. Madrid: Secretaría General Técnica del MECD. Retrieved from http://www.mecd.gob.es/ $\mathrm{dms} / \mathrm{mecd} /$ educacion-mecd/areas-educacion/universidades/estadisticas-informes/datos-cifras/Datosy-Cifras-del-SUE-Curso-2014-2015.pdf

Morley, L. (2001). Producing new workers: Quality, equality and employability in higher education. Quality in Higher Education, 7(2), 131-138. 


\section{A. TENORIO-RODRÍGUEZ ET AL.}

Pastor, J. M., \& Peraita, C. (2014). La inserción laboral de los universitarios españoles. Revista de la Asociación de Sociología de la Educación, 7(1), 252-266.

Purcell, K., Wilton, N., \& Elias, P. (2007). Hard lessons for life-long learners? Age and experience in the graduate labour market. Higher Education Quarterly, 61(1), 57-82.

Teichler, U. (2011). International dimensions of higher education and graduate employment. In J. Allen \& R. van der Velden (Eds.), The flexible professional in the knowledge society: New challenges for higher education. Dordrecht: Springer.

Tholen, G. (2012). Graduate employability and educational context: A comparison between Great Britain and the Netherlands. British Educational Research Journal, 40(1), 1-17.

Yorke, M. (2006). Employability in higher education: What it is-what it is not learning and employability. York: Higher Education Academy.

\section{María A. Tenorio-Rodríguez}

University of Seville

Spain

Teresa Padilla-Carmona

University of Seville

Spain

José González-Monteagudo

University of Seville

Spain 